\title{
A importância dos animais de produção na infecção por Toxoplasma gondii no Brasil
}

\author{
The importance of food animals in the infection for \\ Toxoplasma gondii in Brazil
}

\author{
Patricia Riddell Millar ${ }^{1 *}$; Leila Gatti Sobreiro²; Isabel Cristina Fábregas Bonna³; \\ Maria Regina Reis Amendoeira ${ }^{4}$
}

\begin{abstract}
Resumo
A toxoplasmose é uma das infecções parasitárias mais prevalentes no homem e nos animais, e a sua transmissão tem sido usualmente atribuída à ingestão de carnes cruas ou mal cozidas, de animais de produção infectados, sendo a taxa de infecção destes animais de grande importância para o estudo desta protozoose. Em animais de produção tais como suínos, bovinos, ovinos e caprinos a infecção pelo T. gondii é comum e pode levar a problemas reprodutivos. Animais infectados possuem grande quantidade de cistos do parasita em variados órgãos e músculos e estes não são detectados durante a inspeção da carne nos abatedouros. Esta revisão enfatiza aspectos da protozoose em suínos, caprinos e ovinos, bovinos, eqüinos e aves visando esclarecer o potencial de cada espécie como fonte de infecção do parasita, principalmente no Brasil.
\end{abstract}

Palavras-chave: Toxoplasma gondii, toxoplasmose, animais de abate

\begin{abstract}
Toxoplasmosis is one of the more prevalent parasitic infections in human beings and animals, and its transmission has been usually attributed to the ingestion of undercooked or raw meat from infected livestock, the rate of infection of those animals has great importance for the study of this protozoosis. In farm animals such as swines, sheeps and goats, the infection for the T. gondii is common and can bring reproductive problems. Infected animals possess amount of cysts of the parasite in organs and muscles and these are not detected during the inspection of the meat in the slaughterhouse. This revision emphasizes aspects of toxoplasmosis in swines, sheeps and goats, cattles, horses and chickens aiming to clarify the potential of each species as source of transmission of the parasite, mainly in Brazil.
\end{abstract}

Key words: Toxoplasma gondii, toxoplasmosis, slaughterhouse animals

1 Doutoranda do Programa de Pós-graduação em Medicina Veterinária - Higiene Veterinária e Processamento Tecnológico de Produtos de Origem Animal, Universidade Federal Fluminense (UFF), Niterói, RJ, Brasil. E-mail: patriciariddell@vm.uff.br

2 Docente do Programa de Pós-Graduação em Medicina Veterinária - Higiene Veterinária e Processamento Tecnológico de Produtos de Origem animal, Universidade Federal Fluminense (UFF), Niterói, RJ, Brasil.

3 Doutoranda do Programa de Pós-graduação em Pesquisa Clínica e Doenças Infecciosas do Instituto de Pesquisa Clínica Evandro Chagas, FIOCRUZ, Rio de Janeiro, RJ, Brasil.

4 Pesquisadora Titular, chefe do Laboratório de Toxoplasmose, Departamento de Protozoologia, Instituto Oswaldo Cruz FIOCRUZ, Rio de Janeiro, RJ, Brasil .

* Autor para correspondência 


\section{Introdução}

No início do século XX, Nicolle e Manceaux (1908) relataram a presença de um parasita intracelular no baço e fígado de um roedor, no norte de África, chamado Ctenodactylus gundi. Eles acreditaram se tratar de uma forma particular de Leishmania, denominando-o Leishmania gondii. No Brasil, Splendore (1908) observou o mesmo parasita no coelho, também o comparando ao agente da leishmaniose visceral. Em 1909, no entanto, os primeiros autores constataram que se tratava de um novo parasita, sendo, então, criado o gênero Toxoplasma e a espécie T. gondii (NICOLLE; MANCEAUX, 1909).

A toxoplasmose é uma zoonose de distribuição mundial, que acomete o homem e outros animais de sangue quente. Os felídeos são os únicos hospedeiros que eliminam oocistos do parasita, formas estas resultantes da fase sexuada do ciclo. As condições climáticas são fundamentais para a esporulação dos oocistos no meio-ambiente e, conseqüentemente, na propagação da infecção, pormeio da contaminação de água e alimentos. Os demais animais desempenham o papel de hospedeiros intermediários, transmitindo a protozoose apenas quando sua carne serve para alimentação ou por via congênita (AMENDOEIRA; COSTA; SPALDING, 1999).

O Toxoplasma gondii é um dos mais comuns parasitos encontrados em todo o mundo (CHANG, 1996; TENTER; HECKEROTH; WEISS, 2000), porém, a freqüência da infecção é extremamente variável nas diferentes regiões do planeta e esta variabilidade está ligada a diversos fatores, tais como: padrões culturais da população, hábitos alimentares, idade, procedência rural ou urbana, entre outros (APT et al., 1973; AMENDOEIRA; COSTA; SPALDING, 1999).

Segundo Dubey et al. (2005) existem duas causas principias de transmissão do $T$. gondii para o homem. A infecção pode ocorrer pela ingestão de alimentos ou água contaminada com oocistos esporulados ou ainda pela ingestão de carne crua ou mal cozida contendo cistos teciduais do T. gondii. A proporção da população humana que adquire a infecção pela ingestão de oocistos presentes no ambiente ou pela ingestão de carne é desconhecida, sendo ainda inexistente um teste viável que possa determinar a fonte de infecção para cada indivíduo. No entanto, ainda segundo aqueles autores, as pesquisas soroepidemiológicas que vêem sendo realizadas sugerem que a ingestão inapropriada de carne e produtos cárneos crus ou mal cozidos contendo cistos do $T$. gondii seria a principal via de transmissão para seres humanos em algumas localidades. O manuseio de carnes cruas por donas de casa e magarefes tem sido descrito como um fator de risco de aquisição da infecção (AMENDOEIRA, 1995; DAGUER et al., 2004; ISHIZUKA, 1978a; JAMRA, 1964; MILLAR et al., 2007; SOUZA, 1995).

Os cistos teciduais podem permanecer infectantes em carcaças refrigeradas de 1 a $4^{\circ} \mathrm{C}$ por mais de três semanas e em peças congeladas entre $-1 \mathrm{e}-8^{\circ} \mathrm{C}$ por mais de uma semana (DUBEY, 1988; KOTULA et al., 1991). Em condições experimentais, já foi comprovado que os cistos podem permanecer viáveis após aquecimento a $60^{\circ}$ por até 4 minutos ou $50^{\circ} \mathrm{C}$ por até 10 minutos. Tais dados mostram que alguns cistos podem resistir ao processo de cozimento da carne, principalmente se este processo não ocorrer de modo uniforme, como acontece no aquecimento pelo microondas (DUBEY et al., 1990; LUNDÉN; UGGLA, 1992). O processamento por cura de alguns produtos cárneos pode inviabilizar os cistos dependendo da concentração de sal e temperatura de estocagem. Em condições laboratoriais, os cistos foram mortos quando em solução de $6 \%$ de $\mathrm{NaCl}$ em temperaturas que variavam entre 4 a $20^{\circ} \mathrm{C}$, mas resistiram por diversas semanas em soluções de $0,85 \%, 2,0 \%$ e $3,3 \%$ de sal nas mesmas temperaturas (DUBEY, 1997). Embora, o consumo de carne crua ou mal cozida seja considerado um importante fator de risco para a infecção pelo $T$. gondii, o tipo de carne apontada com o maior risco varia de acordo com a situação de cada região, levando-se em conta a taxa de consumo e a soroprevalência em cada espécie animal na região estudada (COOK et al., 2000). 
Com o advento da Síndrome da Imunodeficiência Adquirida(AIDS) estainfecção tem adquirido grande importância, podendo causar cegueira e encefalite, sendo esta última uma doença letal em $20 \%$ dos pacientes HIV positivos (LUFT; REMINGTON, 1992). Além disso, na forma congênita o parasita infecta a placenta e posteriormente o feto, que pode apresentar lesões severas como hidrocefalia, calcificações cerebrais e retinocoroidite. Pode ocorrer também nascimento de crianças normais que posteriormente apresentem alterações como, por exemplo, a retinocoroidite (HILL; DUBEY, 2002; LEBECH et al., 1996; MOMBRO et al., 2003; PEDREIRA; CAMARGO; LESSER, 2001; SPALDING et al., 2003).

A manifestação dos sinais clínicos da toxoplasmose no homem assim como em outros animais depende, principalmente, da resposta imune do hospedeiro infectado e da virulência da amostra de $T$. gondii (AMENDOEIRA; COSTA; SPALDING, 1999). Assim, a transmissão congênita é importante, tanto para a saúde pública quanto para a sanidade animal e pode ocorrer quando fêmeas não infectadas contraem a toxoplasmose durante a prenhez (HILL; DUBEY, 2002). Em animais podem ser observados os mesmos quadros clínicos que nos humanos. Na revisão sobre Toxoplasma e toxoplasmose de Jacobs (1963), muitos trabalhos são citados para caracterizar os quadros clínicos decorrentes da infecção por $T$. gondii em diferentes espécies. Neste mesmo artigo, em suínos, o autor descreve a ocorrência de lesões no fígado, rins e pulmões, com freqüentes casos de linfoadenopatia, febre, tosse e corioretinites. Em relação aos rebanhos caprinos Pescador et al. (2007) descreveram, além de abortos, lesões dos sistemas respiratório e nervoso em animais provenientes da região Sul do Brasil; para eqüinos, as manifestações clínicas associadas a esta espécie incluem hiperirritabilidade, icoordenação, desordem do sistema nervoso e ocular (DUBEY; PORTERFIELD, 1986; GAZÊTA et al., 1997). De um modo geral, dentre os animais de produção; caprinos, ovinos e suínos são mais sensíveis à infecção quando comparados a bovinos, eqüinos e aves que raramente vão apresentar alguma sintomatologia.

Esta revisão aborda aspectos epidemiológicos da infecção por Toxoplasma gondii em suínos, caprinos/ ovinos, bovinos, eqüinos e aves visando esclarecer o potencial de cada espécie como fonte de transmissão do parasita para os seres humanos, principalmente no Brasil.

\section{Toxoplasmose}

\section{Suínos}

A importância da toxoplasmose suína, além da questão clínica, está relacionada às perdas reprodutivas e às implicações em saúde pública, uma vez que estudos epidemiológicos sugerem que a ingestão de cistos em carne crua ou mal cozida seja uma importante via de transmissão do Toxoplasma gondii para a população humana (APT et al., 1973; FIALHO; ARAÚJO, 2003; JAMRA; DEANE; GUIMARÃES, 1969).

A toxoplasmose natural em suínos foi inicialmente descrita por Farrel et al. (1952) nos Estados Unidos em rebanho que apresentava elevada mortalidade em todas as faixas etárias. No Brasil, o primeiro relato dessa parasitose foi feito por Silva (1959) que descreveu baseado em diagnóstico histológico, um caso espontâneo de toxoplasmose suína no estado de Minas Gerais. Posteriormente, Amaral e Macruz (1969) em São Paulo e Schenk, Lima e Viana (1976) em Minas Gerais isolaram o agente etiológico do diafragma e do cérebro de suínos clinicamente sadios, abatidos para consumo humano.

Em muitas granjas suinícolas tem sido verificada a presença de felinos. A eliminação de oocistos pelos gatos e a conseqüente contaminação da ração, do solo e muitas vezes da água de beber dos animais, por esta forma do parasita, são fontes de infecção de extrema relevância na cadeia de transmissão do parasita. Outras formas de veiculação do $T$. gondii para esta espécie seriam: a ingestão de 
roedores assim como de carnes ou restos de alimentos contaminados com cistos do protozoário, prática muito comum em pequenas criações, ou por transmissão transplacentária (ARAÚJO, 1999; DUBEY et al.,1995). Pode-se dizer de um modo geral, que a freqüência da infecção nesses animais pode ser bastante variável, dependendo principalmente da presença de felinos nas granjas, do tipo de criação, manejo e faixa etária do plantel.

Segundo Fialho e Araújo (2003) os levantamentos sorológicos da toxoplasmose na espécie suína servem para avaliar, além da ocorrência dessa infecção, o risco a que estão expostos os humanos que ingerem carne suína em determinada região. No Brasil, diversos trabalhos vêem, ao longo dos anos, relatando a soroprevalência elevada nesses animais, diferindo de acordo com a área estudada: 9,65\% a 32,8\% em São Paulo (BARCI, 1998; CORREA; SALATA; OLIVEIRA, 1978; ISHIZUKA, 1978b; REBOUÇAS, 1978; SANTOS; AMARAL; SUARÉZ-ARANDA et al., 2000), 4,0\% a 37,84\% no Paraná (CARLETTI et al., 2005; GARCIA et al., 1999; VIDOTTO et al., 1990; TSUTSUI et al., 2003), $7,3 \%$ a $33,75 \%$ no Rio Grande do Sul (ARAÚJO; SOUZA, 1996; FIALHO; ARAÚJO, 2003), 54,1\% em Pernambuco (PORTO et al., 1999).

Além da carne in natura, embutidos crus elaborados com a carne suína podem veicular o T. gondii para seres humanos. Segundo Dubey (1986a), estes produtos são responsáveis por 50 a $75 \%$ de todos os casos de toxoplasmose humana nos Estados Unidos. No Brasil, em algumas localidades a ingestão de embutidos artesanais preparados com carnes desta espécie é uma via de transmissão importante, não só para os indivíduos que ingerem, mas também para aqueles que estão envolvidos com a sua preparação (SPALDING et al., 2005). Dias et al. (2005) reforçam ainda mais esta idéia ao demonstrarem a presença de cistos de Toxoplasma gondii em 13 das 149 (8,7\%) amostras de lingüiças de origem suína tipo frescal, verificada por meio do bioensaio em camundongos.
A alta produção e o considerável consumo de carne suína no Brasil, a elevada disseminação e prevalência do T. gondii associada, segundo Dubey (1988) ao fato de que os cistos podem permanecer viáveis na musculatura dos suínos infectados por até 875 dias e de acordo com Koski (1990), não serem detectáveis ao abate, torna este alimento uma importante via de transmissão da toxoplasmose ao homem quando ingerido cru ou mal cozido.

\section{Ovinos e Caprinos}

Desde 1954, o parasita é descrito como agente de abortamentos na espécie ovina, sendo considerado a maior causa de problemas reprodutivos nesta espécie (UNDERWOOD; ROOK, 1992). Em caprinos o primeiro relato da infecção pelo $T$. gondii foi feito por Feldman e Miller (1956) que identificaram por meio de inquéritos sorológicos a prevalência de $43 \%$ de anticorpos anti-T. gondii em dois grupos de caprinos na área central de Nova York (EUA). Munday e Mason (1979) foram os primeiros a descreverem a toxoplasmose como importante causa de prejuízos reprodutivos em caprinos, e apesar de menos documentada, aparentemente os danos são maiores nesta espécie, acometendo clinicamente também animais adultos (DUBEY, 1987).

Segundo Silva et al. (2003a) tanto para ovinos quanto para caprinos, a principal via de transmissão seria a ingestão de pastagens e água contaminada com oocistos esporulados do parasita.

Segundo Dubey (1990) o T. gondii é mais patogênico para os caprinos quando comparado aos demais animais de abate. Nesta espécie o protozoário frequentemente causa morte fetal, mumificação, natimortalidade, abortos ou nascimento de animais debilitados, ocasionando perda econômica aos caprinocultores. Ainda segundo este autor, as taxas de infecção apontadas não só para rebanhos caprinos, mas também para ovinos são variáveis, e este comportamento deve-se principalmente ao teste sorológico utilizado, à região e idade dos animais estudados. 
Embora sejam poucos os estudos sobre a prevalência do gado ovino no Brasil, já foram descritas prevalências nas regiões sul, onde já foram relatadas positividades elevadas que variam de 39,0\% a 54,6\% (GARCIA et al., 1999; LARSSON; JAMRA; GUIMARÃRS, 1980; OGAWA et al., 2003) e na região nordeste que tem mostrado percentuais consideráveis para esta espécie; assim na Bahia Gondim et al. (1999) relataram um percentual de $18,75 \%$ de indivíduos positivos por meio da técnica de aglutinação em látex (LAT), os autores consideraram positivas as amostras que apresentaram título maior ou igual a 1:64; em Pernambuco Silva et al. (2003a) observaram um percentual mais elevado, 35,3\% dos animais positivos, no entanto, a prova utilizada foi a de Imunofluorescência Indireta e as amostras de soro eram consideradas positivas a partir da diluição 1:16, o que poderia justificar o percentual maior de positivos. Ao pesquisaram anticorpos anti-Toxoplasma em 352 amostras de soros de ovinos, oriundos do estado de São Paulo, por meio das provas de imunofluorescência indireta (RIFI) e hemaglutinação indireta (HAI) Langoni et al. (1999) revelaram 55,1\% de amostras reagentes na RIFI enquanto na HAI somente $30,4 \%$ foram positivas, este achado reforça a importância da padronização das técnicas sorológicas utilizadas no diagnóstico desta infecção.

Alguns trabalhos relatam também o isolamento do T. gondii em tecidos comestíveis da espécie ovina. Sposito-Filha et al. (1992) isolaram 20 cepas de toxoplasma a partir do diafragma de 100 ovinos. Silva e Langoni (2001) isolaram o parasita do cérebro e diafragma de 34 dos 40 ovinos sorologicamente reagentes à imunofluorescência indireta. Estes trabalhos ressaltam a importância desta espécie como fonte de infecção para o homem.

Na espécie caprina a prevalência da infecção também é variável de acordo com a localidade. Na Bahia, Amaral, Santos e Rebouças (1978) observaram um percentual de $10 \%$ de animais positivos. Araújo, Silva e Chaplin (1984) relataram a presença de anticorpos anti-T. gondii em $16,1 \%$ dos caprinos estudados em Porto Alegre, RS. Em 2004, também na região de Porto Alegre no Rio Grande do Sul, foram analisadas 360 amostras de soros de caprinos através das técnicas da Hemaglutinação Indireta (HAI) e Imunofluorescência Indireta (IFI). Através da HAI verificou-se uma freqüência de $19,4 \%$ de soropositividade (70 animais) e pela IFI, de 30\% (108), indicando índices elevados (MACIEL; ARAÚJO, 2004). Recentemente Pescador et al (2007) associaram a Infecção por Toxoplasma gondii com perdas reprodutivas em um rebanho caprino também no Rio Grande do Sul, identificando abortamento, fetos natimortos ou que morriam logo após o parto. No que diz respeito à região sudeste, em Minas Gerais, Machado e Lima (1987) apontam 36,8\% de caprinos positivos em 46 propriedades estudadas, com taxa de $36,1 \%$ entre os rebanhos leiteiros e $11,4 \%$ nos animais de corte enquanto no estado do Rio de Janeiro foi revelada uma prevalência de $15,85 \%$ para toxoplasmose caprina (FREIRE; NORBERG; GAZETA, 1994). Em 1997, Alves et al. (1997) testaram amostras de soros caprinos provenientes de diferentes regiões da Paraíba verificando uma variação na freqüência de anticorpos anti-T. gondii oscilando de zero a 26,0\%. Mainard et al. (2000) estudando, por meio da IFI, propriedades leiteiras de sete diferentes municípios do estado de São Paulo observaram positividade para toxoplasmose $(14,47 \%$ dos 442 caprinos estudados) em todas elas. Mais recentemente, Cavalcante (2004) observou respectivamente, através da IFI e ELISA, que $25,1 \%$ e $25,7 \%$ dos caprinos do Ceará eram positivos para a infecção por T. gondii. Os artigos citados demonstram que a toxoplasmose nesses pequenos ruminantes encontra-se amplamente distribuída em todo território nacional. A infecção toxoplásmica nesta espécie é fato de grande preocupação devido a transmissão da infecção através do leite in natura e de seus subprodutos e da carne e deus derivados quando consumidos quer pelos seres humanos quer por outros animais (SELLA et al., 1994; SILVA et al., 2003a). 
Em relação à taxa de infecção por T.gondi, entre caprinos e ovinos, têm-se observado poucas diferenças, pelo menos quando se estuda uma mesma região. silva et al. (2003a), em amostras de soro de animais em Pernambuco, observaram anticorpos antiT. gondii em 35,3\% dos 173 soros ovinos testados pela IFI e 40,4\% dos 213 soros caprinos.

\section{Bovinos}

Os primeiros casos de bovinos com manifestações clínicas atribuídas ao $T$. gondii foram relatados por Sanger et al. (1953) nos Estados Unidos da América. Embora, segundo Esteban-Redondo et al. (1999), existam poucos trabalhos a respeito dos aspectos clínicos da infecção por $T$. gondii em bovinos, em condições experimentais esses animais parecem ter alta resistência ao protozoário (DUBEY, 1992; DUBEY; THULLIEZ, 1993). Pastagens contaminadas com oocistos são a principal via de transmissão para esses animais (MARANA et al., 1994), por isso o sistema de criação extensivo, muito comum em nosso país favorece a infecção toxoplásmica nos bovinos que, embora suscetíveis à infecção sejam, no entanto, resistente à doença induzida pelo protozoário, não manifestando na grande maioria das vezes sinais clínicos (DUBEY, 1986b; DUBEY; THULLIEZ, 1993; ESTEBANREDONDO; INNES, 1997).

No Brasil, o hábito de ingerir carne crua ou mal cozida principalmente de gado bovino, torna a ingestão deste tipo de produto uma importante via de transmissão, tanto para os humanos quanto para outros animais domésticos carnívoros, que em algumas regiões são alimentados com sobras de carne e vísceras cruas. O isolamento do parasita por Dubey (1992) em intestinos de um bovino, naturalmente infectado por $T$. gondii, e a demonstração feita um ano depois por Dubey e Thulliez (1993), de que cistos teciduais podem permanecer viáveis por períodos superiores há três anos em corações, línguas e fígados de bovinos experimentalmente infectados demonstram a nítida existência do risco de infecção por $T$. gondii pela manipulação não higiênica ou mesmo pelo consumo dessas partes de forma crua ou mal cozida.

Anticorpos para T. gondii têm sido encontrados mundialmente nos bovinos, apesar das taxas de prevalência serem difíceis de determinar (DUBEY; BEATTIE, 1988). No Brasil, estudos realizados sobre a freqüência da infecção tornam possível afirmar que esta protozoose encontra-se amplamente disseminada entre os bovinos por todo país, embora as porcentagens possam variar de acordo com a região. A alta prevalência da presença de anticorpos anti-T.gondii em soros de bovinos vem sendo relatada desde 1978 por Costa et al. (1978) que encontraram 32,3\% de soropositivos no estado de São Paulo e por Costa e Costa (1978) 12\% de reagentes em Minas Gerais, em ambas as pesquisas a técnica utilizada para pesquisa dos anticorpos anti-T. gondii foi a IFI. Dois anos mais tarde, Ferraroni e Marzochi (1980) detectaram, através da hemaglutinação indireta, uma prevalência de $60 \%$ de soropositivos em bovinos na Amazônia. Costa et al. (2001) ao analisarem o soro de bovinos provenientes de municípios rurais de São Paulo e Minas Gerais e Daguer et al. (2004) no estado do Paraná, ambos por meio da RIFI e considerando positivos os soros com titulação maior ou igual a 1:64, observaram que $49,1 \%$ e $41,4 \%$, respectivamente, dos bovinos eram sororeagentes. Desde modo, a alta prevalência de reagentes em bovinos, relatada pela maioria dos autores, reforçam a idéia de que esses animais possam servir de fonte de infecção não só para os consumidores como também para indivíduos cujo trabalho os coloca em contato direto com este tipo de alimento cru ou mal cozido, como por exemplo magarefes e cozinheiros. Outro fator preocupante é a informalidade característica dos mercados alimentares em nosso país que é excepcionalmente relevante no caso de carne bovina onde o abate clandestino corresponde à cerca de $50 \%$ do mercado nacional (AZEVEDO; BANKUTI, 2007). A ingestão dessa carne de procedência duvidosa e que não passou por um processo de inspeção prévia 
aumenta o risco de infecção pelo protozoário para o consumidor. No entanto, quando boas práticas de manejo são oferecidas aos animais, a prevalência da infecção tende a diminuir; como foi mostrado na Bahia por Gondim et al. (1999) que analisando sorologicamente pela técnica de aglutinação em látex 194 bovinos e 104 bubalinos, encontraram positividades bem inferiores às observadas até então, respectivamente, de $1,03 \%$ e $3,85 \%$.

Embora, até o momento, a transmissão toxoplásmica pelo leite in natura só tenha sido descrita como possível na espécie caprina, Marana et al. (1995) em estudo realizado no norte do Paraná encontraram um percentual elevado (48,51\%) de bovinos leiteiros soropositivos para anticopros antiT. gondii. No entanto, este percentual pode variar de acordo com a região estudada, no Rio Grande do Sul Silva et al. (1982/1983) obtiveram um percentual de $3,4 \%$ de animais positivos enquanto no Rio de Janeiro este número foi de 14,8\% (Albuquerque et al., 2005).

\section{Eqüinos}

Os eqüinos parecem ser uma das mais resistentes espécies no desenvolvimento clínico da toxoplasmose (AL-KHALIDI; DUBEY, 1979). Entretanto, sintomas clínicos caracterizados por hiperirritabilidade, incoordenação motora, distúrbios oculares e abortamento já foram relatados (DUBEY; PORTEFIELD, 1986; TURNER; SAVVA, 1991).

Sendo a prevalência do T.gondii em eqüinos provavelmente muito baixa, Dubey et al. (1999), consideram que o risco de contrair a infecção através do consumo da carne desses animais não teria uma importância epidemiológica significativa. No entanto, a carne de eqüídeos pode veicular cistos de $T$. gondii, o que, de certa forma, representaria riscos para a saúde pública em regiões onde é habitual a sua ingestão. Além disso, constituem via de transmissão para animais de zoológico que são alimentados com este tipo de carne, em especial, os felídeos silvestres, que são hospedeiros definitivos do agente, podendo eliminá-lo no meio ambiente por meio das fezes (DUBEY, 1985; Mendonça et al., 2001).

No Brasil, estudos realizados em diferentes regiões buscam esclarecer o papel desses animais na infecção pelo T. gondii. O que tem sido observado é que a prevalência varia de acordo com a localidade. Assim na região centro-oeste existe uma variação de $13,7 \%$ a $32,8 \%$ de sororreagentes (LARANGEIRA; ISHIZUKA; HYAKUTAKE, 1985; VIDOTTO et al., 1997), na região sudeste o percentual encontra-se entre 4,42\% a 41,5\% (COSTA et al., 1986; GAZÊTA et al., 1997; VIDOTTO et al., 1997) e na região sul 12,1\% a 23,4\% (GARCIA et al., 1999; VIDOTTO et al., 1997). Mais recentemente Mendonça et al. (2001) encontrou no estado da Bahia, na região nordeste do país, apenas 1,5\% sororeagentes para T.gondii. Os autores explicam a baixa prevalência nos eqüídeos testados pode ser atribuída a resistência natural destas espécies à infecção pelo $T$. gondii e/ ou a condições ambientais desfavoráveis na região para a disseminação do agente.

Embora, como foi dito acima, a positividade nos eqüinos varie de um local ao outro, de uma forma geral, o que se vê é uma baixa prevalência do $T$. gondii nesta espécie quando a mesma é comparada com outros animais domésticos.

\section{Galinhas domésticas (Gallus domesticus)}

As aves, assim como os roedores, são consideradas importantes hospedeiros intermediários do $T$. gondii uma vez que servem como fonte de infecção do parasita para felinos. Além disso, galinhas domésticas têm sido consideradas como um bom indicador da contaminação do solo por oocistos de T. gondii, sendo utilizadas como animais sentinelas nas regiões de alta prevalência da infecção humana, em função do hábito de ciscar e de sua suscetibilidade ao protozoário (Dubey et al., 2002).

Frangos criados em sistemas intensivos tem menor probabilidade de contato com as vias 
de transmissão do parasita e apresentam baixa prevalência ao T. gondii. Araújo et al. (1989), por meio da IFI, verificaram uma prevalência de apenas 2,8\% em frangos abatidos em matadouros de Porto Alegre, Rio Grande do Sul. Mais recentemente, Meireles, Galisteo Júnior e Andrade (2003) estudando frangos abatidos em matadouros da cidade de Botucatu, São Paulo e não conseguiram identificar a infecção toxoplásmica em nenhuma das 185 amostras analisadas pela técnica de ELISA.

Poroutro lado, a grande procura dos consumidores por produtos diferenciados e de qualidade superior vem influenciando mudanças nos sistemas utilizados para produção de frangos. A sociedade está interessada em sistemas de produção que aumentem o bem-estar na criação de animais. Resgata-se o estilo da criação da galinha caipira e, em um âmbito ainda mais moderno, a criação orgânica. Há mais de dez anos Literak e Hejlicek (1993) já chamavam a atenção para o fato de que galinhas oriundas de pequenas criações podem conter cistos teciduais de $T$. gondii, representando risco de infecção para o homem, principalmente quando estes manipulam carnes sem muita higiene ou por meio do consumo de carnes cruas ou semicozidas.

Dois anos mais tarde Camargo, Antunes e Chiari (1995) realizaram um estudo retrospectivo em 500 indivíduos, para verificar se as variáveis ligadas ao contato com animais no domicílio estariam associadas à ocorrência da infecção humana por T.gondii. Os autores observaram que a proporção de indivíduos que tinham contato com galinhas criadas em fundo de quintal, no passado, ou na residência atual, foi estatisticamente maior no grupo com sorologia reativa do que no grupo com sorologia não reativa. Com isso, sugerem que a relação estabelecida com o grau de contato com galinhas domésticas pode estar associada ao aumento da oportunidade de adquirir a infecção por meio do consumo da carne e/ou de ovos parasitados.

Embora Garcia et al. (2000) tenham revelado, por meio da RIFI e considerando como positivas as diluições maiores ou iguais a 1:16, uma prevalência de $10,3 \%$ de soropositivos em galinhas de criações domésticas (tipo caipira), oriundas de propriedades rurais no município de Jaguapitã, Estado do Paraná, um estudo feito por Silva et al. (2003b) em Campos dos Goytacazes, no Rio de Janeiro, demonstrou, por meio da técnica de aglutinação modificada (MAT) um percentual positivo bem mais elevado (71\%). Mesmo que as técnicas utilizadas para detecção dos anticopros anti-T. gondii da classe IgG nestas pesquisas tenham sido distintas pode-se sugerir que, embora a contaminação ambiental exista no primeiro relato, esta é consideravelmente mais elevada no Rio de Janeiro.

Ainda trabalhando com a técnica da aglutinação modificada Dubey et al (2003) estudando galinhas caipiras no estado do Paraná obtiveram 16/40 (40\%) aves positivas para anticorpos anti- $T$. gondii. Mais recentemente, Dubey et al. (2006) determinaram, através da mesma técnica, a prevalência do $T$. gondii em 50 galinhas de pequenas criações provenientes da região amazônica, sendo encontrados anticorpos antiT. gondii em 33 (66\%) dos animais. Trabalhadores desta mesma localidade que tinham, em sua maioria, contato estreito com os animais, foram, nesse mesmo ano, testados para presença de anticorpos anti- $T$. gondii. Dos 266 soros analisados 195 (73,3\%) foram positivos (CAVALCANTE et al., 2006). Além da alta contaminação ambiental por oocistos do parasita, os resultados expostos indicam que, nesta localidade, as aves podem estar servindo como fonte de infecção direta para a população da região.

De um modo geral, o papel das criações de galinhas em escala industrial, na transmissão toxoplásmica para humanos, têm demonstrado ser de pequena importância, devido ao tipo de manejo e sistema de criação que além de rápido, não permite o contato com felinos e outras fontes de infecção, porém, contrasta com a criação doméstica em pequena escala, do tipo caipira, onde os animais estão sujeitos ao contato com gatos, solo e água contaminados, convivendo durante anos nesse mesmo ambiente. 


\section{Conclusão}

Os felinos, em especial os gatos domésticos, assumem um papel primordial na infecção do Toxoplasma gondii, pois eles eliminam oocistos que contaminamsereshumanos (principalmentenas fases iniciais da vida) e animais. Desta forma os felinos são a chave para o controle da toxoplasma humana e animal, uma vez controlando a contaminação de alimentos, água e solo por oocistos eliminados em suas fezes poderíamos diminuir a transmissão deste parasita. No entanto, o papel dos animais de abate nessa cadeia epidemiológica não deve ser ignorado pelos profissionais de saúde. Embora sejam ainda inexistentes os métodos economicamente viáveis que possam levar ao consumidor um produto seguro no que diz respeito à contaminação pelo T. gondii, outras medidas podem ser tomadas para evitar a infecção através da carne contendo cistos. Inicialmente faz-se necessário um planejamento de saúde animal na origem da cadeia de produção, e da conscientização dos produtores para as formas de controle desta enfermidade (práticas de manejo adequadas, controle de roedores e felinos nas instalações, educação sanitária). Em segundo lugar, a importância da aplicação correta dos métodos empregados atualmente para a destruição dos cistos do T. gondii em carne e derivados (congelamento, defumação, salga, fritura, entre outros), sendo esta condição básica para o controle deste parasita.

\section{Referências}

ALBUQUERQUE, G. R.; MUNHOZ,A. D.; FLAUSINO, W.; SILVA, R. T.; ALMEIDA, C. R. R.; MEDEIROS, S. M.; LOPES, C. W. G. Prevalência de anticorpos anti-Toxoplasma gondii em bovinos leiteiros do vale do Paraíba Sul Fluminense, Estado do Rio de Janeiro. Revista Brasileira de Parasitologia Veterinária, São Paulo, v. 14, n. 3, p. 125-128, 2005.

AL-KHALIDI, N. W. DUBEY, J. P. Prevalence of Toxoplasma gondii infection in horses. Journal of Parasitology, Lawrence, v. 65, n. 2, p. 331-334, 1979.

ALVES, C. J.; VASCONCELLOS, S. A.; NAVARRO, I. T.; BARBOSA, C. S. Avaliação de aglutininas antiToxoplasma em soros de caprinos de cinco centros de criação do nordeste do Brasil. Revista Brasileira de Ciência Veterinária, Niterói, v. 4, n. 2, p. 75-76, 1997.

AMARAL, V.; MACRUZ, R. Toxoplasma gondii, isolamento de amostras a partir de diafragmas de suínos clinicamente sadios, abatidos em matadouros de São Paulo, Brasil. Arquivos do Instituto Biológico, São Paulo, v. 36, n. 1, p. 47-54, 1969.

AMARAL, V.; SANTOS, S. M.; REBOUÇAS, M. M. Sobre a prevalência de anticorpos anti-Toxoplasma em soros de caprinos e ovinos procedentes, respectivamente, dos Estados da Bahia e Rio Grande do Sul, Brasil. $O$ Biológico, São Paulo, v. 45, p. 331-340, 1978.

AMENDOEIRA, M. R. R. Mecanismos de transmissão da toxoplasmose. Anais da Academia Nacional de Medicina, Rio de Janeiro, v. 155, n. 4, p. 224-225, 1995.

AMENDOEIRA, M. R. R.; COSTA, T.; SPALDING, S. M. Toxoplasma gondii Nicolle e Manceaux, 1909 (Apicomplexa: Sarcocystidae) e a Toxoplasmose. Revista Souza Marques, Rio de Janeiro, v. 1, n. 1, p. 1529, 1999.

APT, W.; THIERMANN, E.; NIEDMANN, G.; PASMANIK, S. Toxoplasmosis. Santiago: Universidad de Chile, 1973.

ARAÚJO, F. A. P. Avaliação soroepidemiológica de anticorpos para Toxoplasma gondii, Nicolle e Manceuax, 1909 em soros de suinos (Sus scrofa) da região da grande Erechim, RS-Brasil, detectados através das técnicas de imunofluorescência indireta e imunoenzimática. 1999. Tese (Doutorado em Biologia Parasitária) - Instituto Oswaldo Cruz, Rio de Janeiro.

ARAUJO, F. A. P.; SILVA, N. R. S.; CHAPLIN, E. L. Prevalência de anticorpos toxoplásmicos em soros de caprinos da região da Grande Porto Porto Alegre/RS. Arquivos da Faculdade de Veterinária da UFRGS, Porto Alegre, v. 12, p. 35-40, 1984.

ARAÚJO, F. A. P.; SILVA, N. R. S.; CHAPLIN, E. L.; BIGATTI, L. E. Prevalência de Anticorpos toxoplásmicos em frangos abatidos para consumo humano em Porto Alegre, Rio Grande do Sul. Arquivos da Faculdade de Veterinária da UFRGS, Porto Alegre, v. 17, p. 23-28, 1989.

ARAÚJO, F. A. P.; SOUZA, W. J. S. Prevalência de toxoplasmose em suínos da região de Erechim (RS), detectados pela Imunofluorescência Indireta. In: CONGRESSO PANAMERICANO DE CIÊNCIAS VETERINÁRIAS, 15., 1996, Campo Grande. Anais... Campo Grande: Associação Pan-americana de Ciências Veterinárias e Sociedade Brasileira de Medicina Veterinária, 1996. p. 335. 
AZEVEDO, P.F.; BANKUTI, F.I. Na clandestinidade: o mercado informal de carne bovina. Disponível em: $<$ http:// www.fearp.usp.br/egna/resumos/AzevedoFurquim.pdf> . Acesso em: 20 abr. 2007.

BARCI, L. A. G. Freqüência de anticorpos antiToxoplasma gondii em plantéis de suínos reprodutores no Estado de São Paulo, Brasil. Arquivos do Instituto Biológico, São Paulo, n. 65, v. 1, p. 111-113. 1998.

CAMARGO, M.C.V.; ANTUNES, C.M.F.; CHIARI, C.A. Epidemiologia da Infecção por Toxoplasma gondii no município de Ribeirão das Neves, MG. I. Importância dos animais domésticos como fonte de infecção do $T$. gondii para o homem. Revista da Sociedade Brasileira de Medicina Tropical, Rio de Janeiro, v. 28, n. 3, p. 211214, 1995.

CARLETTI, R. T.; FREIRE, R. L.; SHIMADA, M. T.; RUFFOLO, B. B.; BEGALE, L.P.; LOPES, F.M.R.; NAVARRO, I.T. Prevalência da infecção por Toxoplasma gondii em suínos abatidos no Estado do Paraná, Brasil. Semina Ciências Agrárias, Londrina, v. 26, n. 4, p. 563568,2005 .

CAVALCANTE, A.C.R. Toxoplasmose Caprina no Ceará: Soroepidemiologia e caracterização de cepas do Toxoplasma gondii. 2004. Tese (Doutorado em Parasitologia) - Instituto de Ciências Biológicas da Universidade Federal de Minas Gerais, Belo Horizonte.

CAVALCANTI, G. T.; AGUIAR, D. M.; CAMARGO, L. M. A.; LABRUNA, M. B.; ANDRADE, H. F.; MEIRELLES, L. R.; DUBEY, J. P.; THULLIEZ, P.; DIAS, R. A.; GENNARI, S. M.. Seroprevalence of Toxoplasma gondii antibodies in humans from rural Western Amazon, Brazil. Journal of Parasitology, Lawrence, v. 92, n. 3, p. 647-649, 2006.

CHANG, H. R. The potencial role of azithromycin in the treatment or prophylaxis of toxoplasmosis. Internacional Journal of STD and AIDS, London, v. 7, n. 1, p.18-22, 1996.

COOK, A. J. C.; BUFFOLANO, W.; ZUFFEREY J.; PETERSEN, E.; JENUM P.A.; FOULON, W.; SEMPRINI, A. E.; DUNN, D. T. Sources of Toxoplasma infection in pregnant women: European multicentre casecontrol study. British Medical Journal, London, v. 321, n. 7254 , p. $142-147,2000$.

CORREA, F. M. A.; SALATA, E.; OLIVEIRA, M. R. Toxoplasma gondii: diagnóstico pela prova de imunofluorescência indireta em suínos do estado de São Paulo, Brasil. Arquivos do Instituto Biológico, São Paulo, v. 45, n. 4 , p. 209-212, 1978.

COSTA, A. J.; COSTA, E. P. Freqüência de bovinos reagentes à reação de Imunofluorescência Indireta para
Toxoplasma gondii em Poços de Caldas, MG, Brasil. Arquivos da Escola de Veterinária da Universidade Federal de Minas Gerais, Belo Horizonte, v. 30, n. 1, p. 47-51, 1978.

COSTA, A. J.; ISHIZUKA, M. M.; MARQUES, L. C.; VIDOTTO, O.; ROCHA, U. F.; IKEDA, A. I. Toxoplasmosis frequency in equines from the north region of Sao Paulo State Brazil. Ars Veterinaria, Jaboticabal, v. 2, n. 1, p. 75-79, 1986.

COSTA, A. J.; KASAI, N.; PAULILLO, A. C.; SILVA, M. B.; GALESCO, H. Anticorpos anti-toxoplasma em soros de bovinos do município de Jaboticabal, S.P., Brasil. Arquivos do Instituto Biológico, São Paulo, v. 4, n. 45, p. 299-302, 1978.

COSTA, G. H. N.; CABRAL, D. D.; VARANDAS, N. P.; SOBRAL, E. A.; BORGES, F. A.; CASTAGNOLLI, K. C. Freqüência de anticorpos anti-Neospora caninum e anti-Toxoplasma gondii em soros de bovinos pertencentes aos estados de São Paulo e de Minas Gerais. Semina: Ciências Agrárias, Londrina, v. 22, n.1, p. 61-66, 2001.

DAGUER, H.; VICENTE, R. T.; COSTA, T.; VIRMOND, M. P.; HAMANN, W.; AMENDOEIRA, M. R. R. Soroprevalência de anticorpos anti-Toxoplasma gondii em bovinos e funcionários de matadouros da microrregião de Pato Branco, Paraná, Brasil. Ciência Rural, Santa Maria, v. 34, n. 4, p. 1133-1137, 2004.

DIAS, R. A. F.; NAVARRO, I. T.; RUFFOLO, B. B.; BUGNI, F. M.; CASTRO, M. V.; FREIRE, R. L. Toxoplasma gondii in fresh pork sausage and seroprevalence in butchers from factories in Londrina, Paraná State, Brazil. Revista do Instituto de Medicina Tropical de São Paulo, São Paulo, v. 47, n. 4, p. 185 189, 2005.

DUBEY, J. P. A review of toxoplasmosis in cattle. Veterinary Parasitology, Amsterdam, v. 22, n. 3-4, p. 177-202, 1986b.

. Isolation of Toxoplasma gondii from a Naturally Infected Beef Cow. Journal of Parasitology, Lawrence, v. 78, n. 1, p. 151-153, 1992.

. Long-term persistence of Toxoplasma gondii in tissues of pigs inoculated with $T$ gondii oocysts and effect of freezing on viability of tissue cysts in pork. American Journal of Veterinary Research, Chicago, v. 49, n. 6, p. 910-913, 1988.

Persistence of encysted Toxoplasma gondii in tissues of equids fed oocysts. American Journal of Veterinary Research, Chicago, v. 46, n. 8, p. 1753-1754, 1985.

Status of toxoplasmosis in sheep and goats in the United States. Journal of The American Veterinary 
Medical Association, Schaumburg, v. 196, n. 2, p. 259262, 1990.

Survival of Toxoplasma gondii tissue cysts in $0.85-6 \% \mathrm{NaCl}$ solutions at $4-20{ }^{\circ} \mathrm{C}$. Journal of Parasitology, Lawrence, v. 83, n. 5, p. 946-949, 1997.

Toxoplasmosis. Journal of the American Veterinary Medical Association, Schaumburg, v. 189, n. 2, p. 166-170, 1986a.

Toxoplasmosis in goats. Agri-Practice, Santa Barbara, n.3, v.8, p.43-52, 1987.

DUBEY, J. P.; BEATTIE, C. P. Toxoplasmosis of animals and man. Boca Raton: CRC, 1988.

DUBEY, J. P.; GENNARI, S. M.; LABRUNA, M. B.; CAMARGO, L. M.; VIANNA, M. C.; MARCET, P. L..; LEHMANN, T. Characterization of Toxoplasma gondii isolates in free-range chickens from Amazon, Brazil. The Journal of parasitology, Lawrence, v. 92, n. 1, p. 36-40, 2006.

DUBEY, J. P.; GRAHAM, D. H.; BLACKSTON, C. R..; LEHMANN, T.; GENNARI, S. M.; RAGOZO, A. M.; NISHI, S. M.; SHEN, S. K.; KWOK, O. C. H.; HILL, D. E.; THULLIEZ, P. Biological and genetic characterisation of Toxoplasma gondii isolates from chickens (Gallus domesticus) from São Paulo, Brazil: unexpected findings. International Journal for Parasitology, Oxford, v. 32, n. 1, p. 99-105, 2002.

DUBEY, J. P.; HILL, D. E.; JONES, J. L.; HIGHTOWER, A. W.; KIRKLAND, E.; ROBERTS, J. M.; MARCET, P. L.; LEHMANN, T.; VIANNA, M. C. B.; MISKA, K.; SREEKUMAR, C.; KWOK, O. C. H.; SHEN, S. K.; GAMBLE, H. R. Prevalence of viable Toxoplasma gondii in beef, chicken, and pork from retail meat stores in the United States and risk assesment to consumers. Journal of Parasitology, Lawrence, v.91, n. 5, p. 1082-1093, 2005.

DUBEY, J. P.; KOTULA, A. W.; SHARAR, A.; ANDREWS, C. D.; LINDSAY, D. S. Effect of high temperature on infectivity of Toxoplasma gondii tissue cysts in pork. Journal of Parasitology, Lawrence, v. 76, n.2, p. 201-204, 1990.

DUBEY, J. P.; NAVARRO, I. T.; GRAHAM, D. H.; DAHL, E.; FREIRE, R. L.; PRUDENCIO, L. B.; SREEKUMAR, C.; VIANNA, M. C.; LEHMANN, T. Characterization of Toxoplasma gondii isolates from free-range chickens from Paraná, Brazil. Veterinary Parasitology, Amsterdam, v. 117, n. 3, p. 229-234, 2003.

DUBEY, J. P.; PORTERFIELD, M. L. Toxoplasma like-sporozoa in an aborted equine fetus. Journal of the American Veterinary Medical Association, Schaumburg, v. 11, n. 1, p. 1312-1313, 1986.
DUBEY, J. P.; THULLIEZ, P. Persistence of tissue cysts in edible tissues of cattle fed Toxoplasma gondii oocysts. American Journal of Veterinary Research, Chicago, v. 54, n. 2, p. 270-273, 1993.

DUBEY, J. P.; THULLIEZ, P.; ROMAND, S.; KWOK, O. C. H.; SHEN, S. K.; AND GAMBLE, H. R. Serologic prevalence of Toxoplasma gondii in horses slaughtered for food in North America. Veterinary Parasitology, Amsterdam, v. 86, n. 4, p. 235-238, 1999.

DUBEY, J. P.; WEIGEL, R. M.; SEIGEL, A. M.; KITRON, U. D.; MANNELLI, A.; MITCHELL, M. A.; MATEUSPINILLA, N. E.; THULLIEZ, P.; SHEN, S. K.; KWOK, O. C. H.; TODD, K. S. Risk factors for transmission of Toxoplasma gondii on swine farms in Illinois. Journal of Parasitology, Lawrence, v. 81, n. 5, p. 736-741, 1995.

ESTEBAN-REDONDO, I.; INNES, E. A. Toxoplasma gondii infection in sheep and cattle. Comparative Immunology, Microbiology and Infectious Diseases, Oxford, v. 20, n. 2, p. 191-196, 1997.

ESTEBAN-REDONDO, I.; MALEY, S. W.; THOMSON, K.; NICOLL, S.; WRIGHT, S.; BUXTON, D.; INNES, E. A. Detection of T. gondii in tissues of sheep and cattle following oral infection. Veterinary Parasitology, Amsterdam, v. 86, n. 3, p. 155-171, 1999.

FARREL, R. L.; DOCTON, F. L.; CHAMBERLAIN, D. M.; COLE, C. R. Toxoplasmosis I. Toxoplasma isolated from swine. American Journal of Veterinary Research, Chicago, v. 13, n. 47, p. 181-184. 1952.

FELDMAN, H. A.; MILLER, L. T. Serological study of toxoplasmosis prevalence. American Journal of Hygiene, Baltimore, n. 64, v. 3, p. 320-35, 1956.

FERRARONI, J. J.; MARZOCHI, M. C. A. Prevalência da infecção pelo Toxoplasma gondii em animais domésticos, silvestres e grupamentos da Amazônia. Memórias do Instituto Oswaldo Cruz, Rio de Janeiro, v.75, n.1-2, p.99-109, 1980.

FIALHO, C. G.; ARAUJO, F. A. P. Detecção de anticorpos para Toxoplasma gondii em soro de suínos criados e abatidos em frigoríficos da região da grande Porto Alegre-RS, Brasil. Ciência Rural, Santa Maria, v. 33, n. 5, p. 893-897, 2003.

FREIRE, N.M. S.; NORBERG, A. N.; GAZETA, G. S. Toxoplasmose caprina no Rio de Janeiro. Parasitologia al Dia, Santiago de Chile, v. 18, p. 77-81, 1994.

GARCIA, J. L.; NAVARRO, I. T.; OGAWA, L.; OLIVEIRA, R. C. Soroprevalência do Toxoplasma gondii em suínos, bovinos, ovinos e eqüinos e sua correlação com humanos, felinos e caninos, oriundos de propriedades rurais do norte do Paraná, Brasil. Ciência Rural, Santa Maria, v. 29, n. 1, p. 91-97, 1999. 
GARCIA, J. L.; NAVARRO, L.; OLIVEI, I. T.; OGAWA, R. A., R. C.; MARANA, E. R. M. Soroprevalência do Toxoplasma gondii em galinhas (Gallus gallus domesticus) de criações domésticas, oriundas de propriedades rurais do norte do Paraná, Brasil. Ciência Rural, Santa Maria, v. 30, n. 1, p. 123-127, 2000.

GAZÊTA, G. S.; DUTRA, A. E. A.; NORBERG, A. N.; SERRA-FREIRE, N. M.; SOUZA, W. J. S.; AMORIM, M.; LOPES, L. M. S. Freqüência de anticorpos antiToxoplasma gondii em soros de eqüinos do Rio de Janeiro, Brasil. Revista Brasileira de Parasitologia Veterinária, São Paulo, v. 6, n. 1. P. 97-99, 1997.

GONDIM, L. F. P.; BARBOSA JÚNIOR, H. V.; RIBEIRO FILHO, C. H.; SAEKI, H. Serological survey of antibodies to Toxoplasma gondii in goats, sheep, cattle and water buffaloes in Bahia State, Brazil. Veterinary Parasitology, Amsterdam, n. 3, v. 82, p. 273-276, 1999.

HILL, D.; DUBEY, J. P. Toxoplasma gondii: transmission, diagnosis and prevention. Clinical Microbiology and Infectious, Paris, v. 8, n. 2, p. 634-640, 2002.

ISHIZUKA, M. M. Avaliação da freqüência de reagentes ao Toxoplasma gondii, pela prova de imunofluorescência indireta (anti-IgG), em magarefes. Revista da Faculdade de Medicina Veterinária e Zootecnia da Universidade de São Paulo, São Paulo, v. 15, n. 2, p. 155-158, 1978a.

Avaliação da freqüência de reagentes ao Toxoplasma gondii, pela prova de imunofluorescência indireta, em suínos de matadouro do município de São Paulo. Revista da Faculdade de Medicina Veterinária e Zootecnia da Universidade de São Paulo, São Paulo, v. 15, n. 2, p. 151-154, 1978b.

JACOBS, L. Toxoplasma and toxoplasmosis. Annual Review of Microbiology, Palo Alto, v. 17, p. 429-50. 1963.

JAMRA, L. M. F. Contribuição para epidemiologia da toxoplasmose: inquérito em 100 famílias de uma área da cidade de São Paulo. São Paulo, 1964. Tese (Doutorado em Medicina), Faculdade de Medicina de São Paulo, São Paulo.

JAMRA, L. M. F.; DEANE, M. P.; GUIMARÃES, E. C. On the isolation of Toxoplasma gondii from human food of animal origin: partial results in the city of São Paulo (Brazil). Revista do Instituto de Medicina Tropical de São Paulo, São Paulo, v. 11, n. 3, p. 169-176, 1969.

KOSKI, V. H. Evaluation of ELISA for the detection of Toxoplasma antibodies in swine sera. Acta Veterinaria Scandinavica, Copenhagen, v. 31, p. 413-422, 1990.

KOTULA, A. W.; DUBEY, P.; SHARAR, A. K.; ANDREWS, C. D.; SHEN, S. K.; LINDSAY, D. S. Effect of freezing on the infectivity of toxoplasma gondii tissue cysts in pork. Journal of Food Protection, Des Moines, v. 54, n. 9, p.687-690, 1991.

LANGONI, H.; SILVA, A. V.; ROSA, C.; MARINHO, M. Inquérito soroepidemiológico para a toxoplasmose em ovinos no Estado de São Paulo, Brasil. O Biológico, São Paulo, v. 61, n. 1, p. 35-39, 1999.

LARANGEIRA, N. L.; ISHIZUKA, M. M.; HYAKUTAKE, S. Prevalência da toxoplasmose eqüina avaliada pela técnica de imunofluorescência indireta, Mato Grosso do Sul, Brasil. Boletín de la Oficina Sanitária Panamericana, Washington, v. 99, n. 2, p. 158162, 1985.

LARSSON, C. E.; JAMRA, L. M. F.; GUIMARÃES, E. C. Prevalência da toxoplasmose ovina determinada pela reação de Sabin-Feldman em animais de Uruguaiana, RS, Brasil. Revista de Saúde Pública, São Paulo, v. 14, n. 4, p. 582-588, 1980.

LEBECH, M.; JOYNSON, D. H. M.; SEITZ, H. M.; THULLIEZ, P.; GILBERT, R. E.; DUTTON, G. N.; VLISEN, B.; PETERSEN, E. Classification system and case definitions of Toxoplasma gondii infection in immunocompetent pregnant women and their congenitally infected offspring. European Journal of Clinical Microbiology \& Infectious Diseases, Wiesbaden, v.15, n.10, p. 799-805, 1996.

LITERÁK, I.; HEJLÍCEK, K. Incidence of Toxoplasma gondii in population of domestic birds in the Czech Republic. Avian Pathology, Huntingdon, v. 22, n. 2, p.275-281, 1993.

LUFT, B. J.; REMINGTON, J. S. Toxoplasmic encephalitis in AIDS. Clinical Infectious Disease, Chicago, v. 15, n. 2, p. 211-222, 1992.

LUNDÉN, A.; UGGLA, A. Infectivity of toxoplasma gondii in mutton following curing, smoking, freezing or microwave cooking. International Journal of Food Microbiology, Amsterdan, v. 15, n. 3/4, p, 357-363, 1992.

MACHADO, T. M. M.; LIMA, J. D. Freqüência de anticorpos anti-Toxoplasma gondii em caprinos criados sob diferentes formas de exploração no Estado de Minas Gerais. Arquivos Brasileiros de Medicina Veterinária e Zootecnia, Rio de Janeiro, v. 39, n. 2, p. 255-264, 1987.

MACIEL, K. P.; ARAÚJO, F. A. P. Inquérito sorológico para detecção de anticorpos de Toxoplasma gondii em caprinos (Capra hircus) criados nos municípioos de Gravataí e Vimão, região da grande Porto Alegre, Rio Grande do Sul, Brasil. Revista de Ciências Agroveterinárias, Lages, v. 3, n. 2, p. 121-125, 2004.

MAINARDI, R. S.; STACHISSINI, A. V. M.; LANGONI, H.; PADOVANI, C. R.; MODOLO, J. R. 
Soroprevalência de toxoplasma gondii em rebanhos caprinos no estado de São Paulo. Revista Brasileira de Parasitologia Veterinária, São Paulo, v. 9, n. 2, p. 97-99, 2000.

MARANA, E. R. M.; NAVARRO, I. T.; VIDOTTO, O.; FREIRE, R. L.; LOTT, R. Ocorrência de anticorpos anti-Toxoplasma gondii em bovinos de corte, abatidos em matadouros do norte do Paraná - Brasil. Semina: Ciências Agrárias, Londrina, v. 15, n. 1, p. 38-40, 1994.

MARANA, E. R. M.; VENTURINI, A. C. H.; FREIRE, R. L.; VIDOTTO, O.; NAVARRO, I. T. Ocorrência de anticorpos anti-Toxoplasma gondii em rebanhos de bovinos de leite do norte do Paraná - Brasil. Semina: Ciências Agrárias, Londrina, v. 16, n. 1, p. 40-42, 1995.

MEIRELES, L. R.; GALISTEO JUNIOR, A. F.; ANDRADE JR, H. F. Serological survey of antibodies to Toxoplasma gondii in food animals from São Paulo State, Brazil. Brazilian Journal of Veterinary Research and animal Science, São Paulo, v. 40, n. 4, p. 267-271, 2003.

MENDONÇA, A. O.; CERQUEIRA, E. J. L.; ARAÚJO, W. N.; MORAES-SILVA, E.; SHIMABUKURO, F. H.; SARKIS, D. T.; SHERLOCK, I.; LANGONI, H. Inquérito sorológico para toxoplasmose em equídeos procedentes de duas regiões do Estado da Bahia, Brasil. Semina: Ciências Agrárias, Londrina, v. 22, n.2, p. 115118, 2001.

MILLAR, P. R.; DAGUER, H.; VICENTE, R. T.; COSTA, T.; DE CARLI, A. L.; SOBREIRO, L. G.; AMENDOEIRA, M. R. R. Soroprevalência de anticorpos anti-Toxoplasma gondii em trabalhadores de um matadouro de suínos e em indivíduos com outras atividades na cidade de Palmas, Paraná, Brasil. Ciência Rural, Santa Maria, v. 37, n. 1, p. 292-295, 2007.

MOMBRO, M.; PERATHONER, C.; LEONE, A.; BUTTAFUOCO, V.; ZOTTI, C.; LIEVRE, M. A.; FABRIS, C. Congenital toxoplasmosis: assessment of risk to newborns in confirmed and uncertain maternal infection. European Journal of Pediatrics, v.162, n.10, p.703-706, 2003.

MUNDAY, B. L.; MASON, R. W. Toxoplasmosis as a cause of perinatal death in goats. Australian Veterinary Journal, Brunswick, v. 55, n. 10, p. 485-487, 1979.

NICOLLE, C.; MANCEAUX, L. Sur un protozoaire nouveau du gondi. Comptes Rendus de l'Academie des sciences, Paris, v. 148, p. 369-372. 1909.

Sur une infection à corps de Leishman (ou organismes voisins) du dondi. Comptes Rendus de l'Academie des sciences, Paris, v. 147, p. 763-766, 1908.
OGAWA, L.; NAVARRO, I. T.; FREIRE, R. L.; OLIVEIRA, R. C.; VIDOTTO, O. Ocorrência de anticorpos anti-Toxoplasma gondii em ovinos da região de Londrina no Estado do Paraná. Semina: Ciências Agrárias, Londrina, v. 24, n. 1, p. 57-62, 2003

PEDREIRA, D. A. L.; CAMARGO, M. E.; LESER, P. G. Toxoplasmosis: will the time ever come? Ultrasound in Obstetrics and Gynecology, Carnforth, v.17, n. 6, p.459463, 2001.

PESCADOR, C. A.; OLIVEIRA, E. C.; PEDROSO, P. M. O.; BANDARRA, P. M.; OKUDA, L. H.; CORBELLINI, L. G.; DRIEMEIER, D. Perdas reprodutivas associadas com infecção por Toxoplasma gondii em caprinos no sul do Brasil. Pesquisa Veterinária Brasileira, Rio de Janeiro, v. 27, n.4, p.167-171, 2007.

PORTO, W. J. N.; RIBEIRO, T. C. E. S.; LEITE, A. S.; ALVES, L. C.; BARBOSA, C. L.; MOTA, R. A.; PEREIRA, G. C.; CARVAlHO JÚNIOR, G. M. Frequência de suínos sororeagentes para Toxoplasma gondii na região metropolitana do Recife. In: CONGRESSO BRASILEIRO DE PARASITOLOGIA VETERINÁRIA, 11., Salvador, 1999. Anais... Salvador: Colégio Brasileiro de Parasitologia Veterinária, 1999. p. 219.

SANGER, V. L.; CHAMBERLAIN, D. M.; CHAMBERLAIN, K. W.; COLE, C. R.; FARRELL, R. L. Toxoplasmosis. V. Isolation of Toxoplasma from cattle. Journal of American Veterinary Medical Association, Ithaca, v. 123, n. 917, p. 87-91, 1953.

SANTOS, S. M.; AMARAL, V.; REBOUÇAS, M. M. Prevalência de anticorpos antitoxoplasma, por hemoaglutinação indireta, em soros de suínos provenientes de diferentes municípios do estado de São Paulo. O Biológico, São Paulo, n. 44, p. 149-153, 1978.'

SCHENK, M. A. M.; LIMA, J. D.; VIANA, F. C. Freqüência da toxoplasmose em suínos abatidos em Belo Horizonte, Minas Gerais. Arquivos da Escola de Veterinária da Universidade Federal de Minas Gerais, Belo Horizonte, v. 28, n. 3, p. 261-266, 1976.

SELLA,M.Z.; NAVARRO,J.T.;VIDOTTO,O.;FREIRE, R. L.; SHIDA, P. N. Epidemiologia da toxoplasmose caprina levantamento sorológico do Toxoplasma gondii em caprinos leiteiros na micro região de Londrina, Paraná, Brasil. Revista Brasileira de Parasitologia Veterinária, São Paulo, v. 3, n. 1, p. 13-16, 1994.

SILVA, A. V.; CUNHA, E. L. P.; MEIRELES, L. R.; GOTTSCHALK, S.; MOTA, R. A.; LANGONI, H. Toxoplasmose em Ovinos e Caprinos: Estudo 
Soroepidemiológico em Duas Regiões do Estado de Pernambuco, Brasil. Ciência Rural, Santa Maria, v. 33, n. 1, p. 115-119, 2003a.

SILVA, A. V.; LANGONI, H. The detection of Toxoplasma gondii by comparing citology, histopathology, bioassay in mice, and the polymerase chain reaction (PCR). Veterinary Parasitology, Amsterdam, v. 97, n. 3, p. 191198, 2001.

SILVA, D. S.; BAHIA-OLIVEIRA, L. M. G.; SHEN, S. K.; KWOK, O. C. H.; LEHMAN, T.; DUBEY, J. P. Prevalence of Toxoplasma gondii in chickens from a area in southern Brazil Highly Endemic to Humans. Journal of Parasitology, Lawrence, v. 89, n. 2, p. 394-396, 2003 b.

SILVA, J. M. L. Sobre um caso de toxoplasmose espontânea em suínos. Arquivos da Escola Superior de Veterinária da Universidade Rural de Minas Gerais, v. 12, p. 425-428, 1959.

SILVA, N. R. S.; CHAPLIN, E. L.; ARAÚJO, F. A. P.; MENDES, L. D. V. Freqüência de anticorpos de Toxoplasma gondii em soro de bovinos de leite da grande Porto Alegre, RS. Arquivos da faculdade de Veterinária da UFRGS, Porto Alegre, v.10, p.81-84, 1982/1983.

SOUZA, W. J. S. Epidemiologia da toxoplasmose: avaliação sorológica de suinos e trabalhadores em abatedouros na mesorregião do Grande Rio de Janeiro. Itaguaí, 1995. Tese. (Doutorado em Parasitologia Veterinária) - Universidade Federal Rural do Rio de Janeiro, Rio de Janeiro, 1995.

SPALDING, S. M.; AMENDOEIRA, M. R. R.; KLEIN, C. H.; RIBEIRO, L. C. Serological screening and toxoplasmosis exposure factors among pregnant women in South of Brazil. Revista da Sociedade Brasileira de Medicina Tropical, Rio de Janeiro, v. 38, n. 2, p.173-177, 2005.

SPALDING, S. M.; AMENDOEIRA, M. R. R.; RIBEIRO, L. C.; SILVEIRA, C.; GARCIA, A. P.; CAMILLO-COURA, L. Prospective study of pregnant women and babies with risk of congenital toxoplasmosis in municipal district of Rio Grande do Sul. Revista da Sociedade Brasileira de Medicina Tropical, Rio de Janeiro, v.31, n.4, p.483-91, 2003.

SPLENDORE, A. Um nuovo protozoa parassita dei conigli incontrato nelle lesioni anatomiche d'una malattia Che ricorda in molti ponti il kala-azar dell'uomo. Revista Sociedade de Sciencia de São Paulo, São Paulo, v. 3, p. 109-12, 1908.
SPÓSITO FILHA, E.; AMARAL, V. D. O.; MACRUZ, R.; REBOUÇAS, M. M.; SANTOS, S. M.; DRUMOND, L. S. Toxoplasma gondii em ovinos: Isolamento do parasita a partir de diafragmas de animais procedentes do Estado do Rio Grande do Sul e abatidos em matadouros de São Paulo, para consumo humano. Revista Brasileira de Parasitologia Veterinária, São Paulo, v. 1, n. 2, p. 117-119, 1992.

SUARÉZ-ARANDA,F.; GALISTEO,A.J.;HIRAMOTO, R. M.; CARDOSO, R. P.; MEIRELES, L. R.; MIGUEL, O.; ANDRADE, H. F. J. R. The prevalence and avidity of Toxoplasma gondii IgG antibodies in pigs from Brazil and Peru. Veterinary Parasitology, Amsterdam, v. 91, n. 1, p. 23-32, 2000.

TENTER, A. M.; HECKEROTH, A. R.; WEISS, L. M. Toxoplasma gondii: from animals to humans. International Journal for Parasitology, Oxford, v. 30, n. 12-13, p. 1217-1258, 2000.

TSUTSUI, V. S.; NAVARRO, I. T.; FREIRE, R. L.; FREITAS, J. C.; PRUDENCIO, L.B.; DELBEM, A.C.B.; MARANA, E.R.M. Soroepidemiologia e fatores associados à transmissão do Toxoplasma gondii em suínos no norte do Paraná. Archives of Veterinary Science, Curitiba, v. 8, n. 2, p. 27-34, 2003.

TURNER, C. B.; SAVVA, D. Detection of Toxoplasma gondii in equine eyes. Veterinary Record, London, v. 129, n. 6, p. 128, 1991.

UNDERWOOD, W. J.; ROOK, J. S. Toxoplasmosis infection in sheep. The Compendium on Continued Education in Veterinary Practice, New York, v. 14, n. 8, p. 1543-1549, 1992.

VIDOTTO, O.; KANO, F. S.; FREIRE, R. L.; MITSUKA, R.; OGAWA, L.; BANESI, G.; NAVARRO, I. T.; FRANCISCON, F. S. G. Ocorrência de anticorpos antiToxoplasma gondii em equinos procedentes de quatro Estados (SP, PR, MS e MT) abatidos em Apucarana, PR. Semina: Ciências Agrárias, Londrina, v. 18, n. 1, p. 9-13, 1997.

VIDOTTO, O.; NAVARRO, I. T.; GIRALDI, N.; MITSUKA, R.; FREIRE, R. L. Estudos epidemiológicos da toxoplasmose em suínos da região de Londrina - PR. Semina: Ciências Agrárias, Londrina, v. 11, n. 1, p. 5359, 1990. 